\title{
Algumas pistas sobre o marketing ambiental pelo olhar da psicossociologia
}

\author{
Eliane Monteiro de Almeida, (D) ${ }^{\star}$ Frederico Augusto Tavares Junior, (D) Giselle Gama Torres Ferreira (D) \\ Universidade Federal do Rio de Janeiro, Rio de Janeiro, RJ, Brasil
}

\section{Resumo}

\begin{abstract}
Este ensaio teórico busca uma reflexão crítica sobre o marketing ambiental, pelo olhar da psicossociologia, para discutir sobre o conceito de ecosofia, enfocando como ocorrem os processos de agenciamento de enunciação de um "rizoma verde" na captura de modos de ser "ecológico" ou "ecopsicossocial”. Desta forma, o presente trabalho visa trazer uma proposta contra-hegemônica, consubstanciada pelo olhar da esquizoanálise, de modo a romper antigas formas de pensar e produzir conhecimento na pesquisa em ciências humanas e sociais. O objetivo central é pensar sob a égide do conceito das três ecologias - conforme postulado por Félix Guattari - por meio dos paradigmas da sociedade de controle e do Capitalismo Mundial Integrado (CMI) como são produzidas as "subjetividades verdes" que exploram recursos naturais e produtilizam a natureza. A pesquisa é bibliográfica, fundamentada nas pistas teóricas trilhadas por Félix Guattari, Gilles Deleuze e por outros autores que dialogam com seus pensamentos. As pistas sugerem uma discussão psicossocial que desvela novos rumos para a ressignificação do marketing ambiental, apontando para a necessidade de se pensar um novo "marketing ecosófico" baseado nas três ecologias, bem como pensado sob um novo paradigma ético-político e estético, no qual as relações socioambientais sejam priorizadas.
\end{abstract}

Palavras-chave: marketing ecosófico; ecosofia; rizoma verde; subjetividade.

\section{Some clues about environmental marketing through the view of psychsociology}

\begin{abstract}
This theoretical essay seeks a critical reflection on environmental marketing, through the view of psychosociology, to discuss under the concept of ecosophy as occur the processes of agency of enunciation of a "green rhizome" in the capture of modes of being "ecological" or "ecopsicossocial". Thus, the study aims to bring a counter-hegemonic proposal, consubstantiated by the schizoanalytic view, in order to break with old ways of thinking and produce knowledge in research in human and social sciences. The central objective is to think under the aegis of the concept of the three ecologies - as postulated by Félix Guattari- through the paradigms of the control society and Integrated World Capitalism (IWC) howare produced the "green subjectivities" thatexploit natural resources and produce nature. The research is bibliographical, based on the theoretical tracks traced by Félix Guattari, Gilles Deleuze and other authors who dialogue with their thoughts. The clues suggest a psychosocial discussion that reveals new directions for the re-signification of environmental marketing, pointing to the need to think about a new "ecosophy-marketing" based on the three ecologies, as well as thinking under a new ethical paradigm - political and aesthetic, in which socio-environmental relations are prioritized.
\end{abstract}

Keywords: ecosophy marketing; ecosophy; green rhizome; subjectivity.

\section{Introdução}

A produção capitalista e o consumo contemporâneo tornaram-se preocupação estratégica dos ambientalistas e do sistema empresarial e, por conseguinte, a sociedade de consumidores passa a incorporar novos comportamentos de consumo, que percebem e valorizam produtos e serviços com apelos socioambientais. À luz desta questão, as organizações têm voltado seus esforços para refletir novos modos de produção e consumo que minimizem os impactos socioambientais, porém buscam agenciar e capturar subjetividades e, assim, criar novos modos de ser (FERREIRA et al., 2017; GIFFORD, 2014)

Segundo Deleuze (2012, p. 16), “A subjetividade é determinada como um efeito, é uma impressão de reflexão". Assim é o processo de elaboração dos agenciamentos de enunciação do "marketing verde" (OTTMAN, 1994) que, por meio dos "kits de subjetividade verde" (SILVA; TAVARES, 2016) podem, por exemplo, ser transformados em produtos verdes e apresentados, até mesmo, contendo selos verdes não certificados para a captura de consumidores ecológicos ou "ecopsicossociais".

\footnotetext{
^Endereço para correspondência: Universidade Federal do Rio de Janeiro. Av. Pasteur, 250 - Urca - Rio de Janeiro, RJ - Brasil. CEP: 22290-240. Emails: elianealmeida@ufrj.br,frederico.tavares@eco.ufri.br,giselletorres.com@gmail.com Os dados completos dos autores encontram-se ao final do artigo.
}

Dessa forma, o marketing ambiental, como dispositivo do capital (PELBART, 2003; PONTES; TAVARES, 2017), passa a ter um papel relevante no posicionamento empresarial das marcas ecológicas e na criação dos novos consumidores "ecopsicossociais". Destaca-se que neste processo a esquizoanálise, conceito postulado por Guattari e Deleuze, contribui para uma reflexão sobre as ações de marketing. Isso é possível, pois Strey (2013, p. 131) menciona que: "[...] Deste modo, ela recusa a ideia de que o desejo e a subjetividade estejam centrados nos indivíduos, mas, sim, afirma que eles são construídos socialmente".

Sendo assim, é possível discutir o marketing ambiental pela visão psicossocial e inferir que o marketing formula suas contradições por trás do discurso verde e dos agenciamentos coletivos que se formam e se agenciam nas redes sociotécnicas (LATOUR, 2012).

A partir disso, este ensaio teórico tem como pista uma reflexão do marketing ambiental pensado não pelo manejo do marketing sistêmico da Escola de Chicago (MATTELART, 2011), mas sim pela visão da ecosofia das marcas (PONTES; TAVARES, 2017), na qual se discutem as três ecologias (mental, social e ambiental), originalmente formuladas por Guattari (2001). Nesse sentido, refletir a lógica dos processos psicossociais pelo conceito de "ecosofia" como pensamento motor 
para dialogar com a temática da subjetividade e sua intersecção com os conceitos de rizoma e agenciamento de enunciação, a fim de apontar desdobramentos e provocações para o marketing, através do campo psicossocial, é o processo que conduz este ensaio teórico.

Desta forma, o presente trabalho visa trazer uma proposta contra-hegemônica, consubstanciada na teoria da esquizoanálise, elaborada por Deleuze e Guattari (2004), de modo a romper com antigas formas de pensar e produzir conhecimento na pesquisa em ciências humanas e sociais. Assim, a perspectiva teórica psicossocial apresentada neste ensaio intenta romper com sistemas "molares" ou, em outras palavras, com as envelhecidas fórmulas conservadoras de sistemas, tais como: fábricas, indústrias, governos, escolas etc., para trazer "práticas modernas"-ou um conjunto de ações "moleculares"-, num processo de revitalização do passado (DELEUZE; GUATTARI, 2011a).

Desse modo, o objetivo central deste estudo é refletir como são produzidas as "subjetividades verdes" que exploram os recursos naturais e produtilizam a natureza, dado que, na contemporaneidade, o indivíduo é constantemente estimulado por propostas ecoamigáveis, o que faz emergir consumidores que assumem novos modos de ser e ter "ecopsicossociais". A contribuição deste ensaio, portanto, é propor uma nova visão para o marketing ambiental, pelo olhar psicossocial, rompendo formas de pensamento pré-estabelecidas nesta área do conhecimento.

Destarte, este estudo visa identificar, por meio das teorias pós-estruturalistas, como são elaborados os agenciamentos coletivos de enunciação do consumo verde na era pós-moderna e globalizada, na qual todos se agenciam e se multiplicam em rede de forma rizomática, por meio de um regime de Biopoder (HARDT; NEGRI, 2001; TAVARES; IRVING, 2010).

Essa discussão se faz relevante tendo em vista que para Guattari a subjetividade relaciona-se à exterioridade humana, ou seja, toda subjetividade é fundamentalmente maquinada, fabricada, modelada e consumida (GUATTARI, 1992). Da mesma forma, segundo Strey (2013, p. 132) "O desejo é aqui entendido como movimentos intensivos que se expressam através da subjetividade enquanto modo dos indivíduos perceberem o mundo e articularem as suas relações sociais". Além disso, a subjetividade é constantemente alimentada pelo capitalismo contemporâneo - descentralizado, rizomático, mundial e integrado - impulsionando uma lógica coletiva organizada por uma nova ordem de consumo ecológico que se configura em "kits de subjetividade verde" (VARGAS; TAVARES, 2018).

Assim, para Tavares e Irving (2013), surge uma nova ordem de mercado que produtiliza a natureza e utiliza um "capital verde" que, igualmente: "são fluxos sociais, materiais e de signos que são a objetividade do desejo" (GUATTARI, 1981, p. 8). É pela via do marketing ambiental que a dinâmica do capital passa a se dar em rede e virtualmente (FERREIRA; TAVARES, 2017) numa condição de comunicação rizomática, na qual o consumidor tanto produz quanto é produzido pelo atravessamento das redes sociotécnicas, numa revolução molar-molecular entre organizações, agentes sociais, consumidores e mass-media "máquina de guerra"/"máquina de desejo"/"máquina teórica" (GUATTARI, 1981). Os agenciamentos de enunciação do "rizoma verde" são produzidos de forma coletiva por redes sociotécnicas, numa relação híbrida entre humanos e não humanos (LATOUR, 1987, 2005). Da mesma forma, o conceito de coletivo pode ser compreendido como rede social (ESCÓSSIA; KASTRUP, 2005; CALLON; LAW, 1997) numa imanente relação onde todos se agenciam e são agenciados por diversas forças constituintes deste plano comum, pois toda subjetividade é coletiva e produzida por um agenciamento coletivo de enunciação que se virtualiza e se materializa ao mesmo tempo (KASTRUP, 2013).

Ampliando esta reflexão, infere-se que o agenciamento do "rizoma verde" passa a ocorrer de forma fluida, uma vez que as empresas nos dias atuais comercializam seus bens e serviços por meio de diversos canais híbridos, canais de comércio eletrônico e redes virtuais. Esta virtualização propicia uma interação de fluxos e contrafluxos entre os consumidores e as marcas. Desta forma, o marketing explora a comunicação entre os consumidores, que passam a interagir diretamente com as marcas, dando sugestões e opiniões sobre seus produtos e serviços.

Corroborando com esse entendimento, Kotler e Keller (2012) afirmam que: “A propaganda de massa já não é tão eficiente quanto antes e, por isso, as organizações passaram a explorar novas formas de comunicação, como o marketing de experiência, o de entretenimento e o viral" (KOTLER; KELLER, 2012, p. 20).

Sendo assim, a internet passa a ser considerada um território privilegiado da vigilância de massa, o que torna possível conectar milhões de pessoas pelo mundo (DOMINGUES, 2016). Esse novo modo de viver conectado em redes sociotécnicas, no qual o indivíduo passa a trocar informações sobre seu modo de vida, faz surgir novos modos de ser e novas dimensões, que podem ser de ordem psíquica, social ou ambiental (GUATTARI, 2001; PONTES; TAVARES, 2017).

Nesse sentido, infere-se que: “A globalização da economia e os avanços tecnológicos, especialmente a mídia eletrônica, aproximam universos de toda espécie, situados em qualquer ponto do planeta, numa variabilidade e numa densificação cada vez maiores" (ROLNIK, 1997, p. 19).

A partir deste ponto, o presente ensaio propõe uma reflexão crítica cuja preocupação inicial é explorar a relação do marketing ambiental pelo olhar da psicossociologia, apresentado sob o conceito de ecosofia, originalmente postulado por Guattari (2001) em sua obra Três ecologias, a qual estabelece três esferas de relações (mental, social e ambiental). Além disso, o presente ensaio procura refletir os demais conceitos de rizoma e agenciamento de enunciação, usualmente apresentados na literatura de Gilles Deleuze e Félix Guattari, trazendo, também, a noção de redes, de Bruno Latour.

Fractal, Rev. Psicol., v. 31 - n. esp., p. 269-275, set. 2019 
Nesse contexto, os tópicos a seguir fazem, primeiro, uma análise dos processos do marketing ambiental pelo olhar da psicossociologia num contrafluxo epistemológico, buscando discutir e identificar como o capitalismo rizomático opera na produção de subjetivação exercida pelas marcas verdes. Também, analisa-se como são elaborados os processos de agenciamento de enunciação para divulgação e comercialização dos "kits de subjetividade verde" e, ou produtos e serviços ecológicos. O segundo tópico estabelece o conceito de ecosofia no contexto da sociedade de controle, de modo a entender o CMI em junção com os múltiplos atores sociais que se agenciam e são agenciados e que estão envolvidos na trama do "rizoma verde". O terceiro tópico é dedicado justamente a definir os processos do CMI: rizoma e agenciamento de enunciação. O tópico seguinte debruça-se à reflexão crítica do marketing sistêmico ao "marketing psicossocial", apontando novas pistas sobre o marketing ambiental. E, por último, apresentam-se as considerações finais que, numa reflexão crítica, trazem um contrafluxo de pensamento sobre o marketing ambiental.

\section{Psicossociologia e subjetividade: o marketing ambiental pelo olhar da psicossociologia}

Este ensaio teórico utiliza em seu esboço os conceitos de Deleuze e Guattari para discutir o marketing ambiental pelo olhar psicossocial. Nesse sentido, a obra de Deleuze e Guattari, no que se refere ao estudo da subjetividade, nos auxilia a compreender o processo de enunciação do marketing ambiental como responsável pela geração de subjetividades produzidas como "kits de subjetividade verde" ou, em muitos casos, por meio de estratégias de "botox ambiental" ou "greenwashing" (TAVARES et al., 2017). Assim, no âmbito do capitalismo rizomático constitui-se "uma poderosa cartografia para nos movermos nos meandros dos processos de subjetivação contemporâneos, cartografia essa que ainda está por ser descoberta e explorada" (ROLNIK, 2000, p. 10). A subjetividade é maquinada por um novo processo de produção de interações humanas e não humanas, tais como: "'Corpo sem Órgãos'. É nesse corpo que os encontros com o outro, não só humano, geram intensidades [...] 'singularidades pré-individuais' ou 'proto-subjetivas'. Os agenciamentos de tais singularidades são exatamente aquilo que irá vazar dos contornos dos indivíduos, e que acaba levando à sua reconfiguração" (ROLNIK, 2000, p. 10).

Visto, também, de outra forma: "Um agenciamento é precisamente este crescimento das dimensões numa multiplicidade que muda necessariamente de natureza à medida que ela aumenta conexões" (DELEUZE; GUATTARI, 2011b, p. 24).

Indo um pouco mais além, Pelbart (2003) defende que essa é a lógica do Império. Isto é, a lógica dos jogos de poder do capitalismo pós-moderno, descentralizado e desterritorializado, que conecta a sociedade de controle à globalização, interligando o capitalismo a novos modos de "ser" e "viver" (TAVARES et al., 2016). É esta mesma lógica que Deleuze e Guattari em Mil Platôs chamam de "axiomas do capitalismo". Assim, aproveitando-se desse capitalismo contemporâneo, desterritorializado, mundial e integrado, o marketing ambiental utiliza a subjetividade como matéria-prima, produzindo e gerando uma prática de modelagem marcária (FERREIRA; TAVARES, 2017). Além disso, percebe-se que a subjetividade humana é afetada não somente pelo consumo, mas pelo que o produto representa ao indivíduo em seu estilo de vida. O produto e a marca simbolizam muito mais do que o indivíduo necessita; estes objetos e símbolos passam a representar os novos seres "ecopsicossociais" ou "[...] uma "vida melhor', a partir do diferencial de imagem construída pelo denominado 'consumo verde', como atitude de fazer o bem, de um agir política e ecologicamente corretos" (TAVARES, 2014, p. 90).

Contudo, é importante ressaltar que a sociedade contemporânea vem passando por alterações socioambientais dentro de um cenário de crises econômicas e políticas intrínsecas ao mundo globalizado e, é nesse contexto que Guattari evidencia: “[...] corremos o risco de não mais haver história humana se a humanidade não reassumir a si mesma radicalmente. Por todos os meios possíveis, trata-se de conjurar o crescimento entrópico da subjetividade dominante" (GUATTARI, 2001, p. 54).

Para tanto, de modo a se pensar uma mudança ético-política e estética (GUATTARI, 2001), no próximo tópico analisa-se o conceito ecosófico nas transações da sociedade de controle.

\section{O conceito ecosófico nas transações da sociedade de controle}

Seguindo a mesma lógica de rede, a perspectiva ecosófica proposta por Guattari aspira pronunciar em suas reflexões um processo de articulação ético-político e estético exercido pelas marcas por meio da publicidade (TAVARES; PONTES, 2014), que tem como pano de fundo a "sociedade de controle" operando no campo dos agenciamentos de enunciação dos processos publicitários, e alimentado pelo Capitalismo Mundial Integrado (CMI) (GUATTARI, 2001).

Desta forma é que o capitalismo rizomático contemporâneo "trabalha para que os setores indiretamente ligados à máquina de produção tornem-se coadjuvantes ao setor produtivo e para que também produzam meios de contribuir para a lógica do consumo" (FERREIRA; TAVARES, 2017, p. 51). Seguindo esta pista, e tendo como pano de fundo a sociedade de controle que é alimentada pelo CMI, Deleuze e Guattari nos convidam a pensar se "essa fase paroxística de laminagem das subjetividades, dos bens e do meio ambiente não está sendo levada a entrar num período de declínio" (GUATTARI, 2001, p. 12). E é nesse sentido que o marketing ambiental agencia um "movimento de múltiplas faces dando lugar a instâncias e dispositivos ao mesmo tempo analíticos e produtores de subjetividade" (GUATTARI, 2001, p. 53). Igualmente, pode-se dizer que nessa produção capitalística do "rizoma verde" se encontram diversos atores sociais (LATOUR, 2012), tais como indústria, comércio, organizações públicas e privadas, transformando a matéria-prima, que é um recurso natural, em produtos ecológicos ou 
verdes. Nessa evolução do capitalismo rizomático, pela visão psicossocial, dizer-se-ia que o marketing passa a operar não somente pelas ciências econômicas e sociais, como também por diversas disciplinas que, desta forma, fomentam múltiplas parcerias ou "parcerias rizomáticas" e "agenciamentos maquínicos". Esta nova potência, denominada "natureza dos agenciamentos", indica que: “já não há nem homem nem natureza, mas unicamente um processo que os produz um no outro, e liga as máquinas"(DELEUZE; GUATTARI, 2004, p. 8). Aprofundando esta reflexão, o texto Post-Scriptum sobre a sociedade de controle resume que: "o marketing é agora o instrumento de controle social, e forma a raça impudente de nossos senhores" (DELEUZE, 1992, p. 224).

Para compreender com maior fundamento esse novo modo de produção do capitalismo, observa-se no próximo tópico como os processos do CMI formam o rizoma e produzem os agenciamentos de enunciação.

\section{Os processos do CMI: rizoma e agenciamento de enunciação}

Segundo Deleuze e Guattari (2011b, p. 25), “Todo rizoma compreende linhas de segmentaridade segundo as quais ele é estratificado, territorializado, organizado, significado, atribuído, etc." Assim, é por meio do capitalismo rizomático que os agenciamentos de enunciação se formam e "colocam em contato subjetividades - constelações singulares de fluxos sociais, materiais e de signos -, criando uma área-de-intimidade-e-desejo onde um e outro se metamorfoseiam. Nunca paralelamente" (GUATTARI, 1981, p. 9). A partir disso, evidencia-se a contribuição da ordem capitalística para que o marketing ambiental atue de forma conexionista e desterritorializada, se infiltrando nas mentes humanas por meios das representações inconscientes e na cultura de um modo geral, agenciando modos de ser, pois: "Um agenciamento é precisamente este crescimento das dimensões numa multiplicidade que muda necessariamente de natureza à medida que ela aumenta suas conexões" (DELEUZE; GUATTARI, 2011a, p. 24).

Além disso, ressalta-se que todas estas estratégias de agenciamento alimentam o "capitalismo rizomático" na espécie de um rizoma. ${ }^{1}$ Assim, Deleuze e Guattari (2011a, p. 22) relatam que: "Num rizoma, ao contrário, cada traço não remete necessariamente a um traço linguístico: cadeias semióticas de toda natureza são aí conectadas a modos de codificação muito diversos, cadeias biológicas, políticas, econômicas, etc."

À luz desta problemática, entende-se que o marketing ambiental é constantemente alimentado pelo capitalismo rizomático ou pelo CMI, e que suas estratégias comerciais para a venda de produtos sustentáveis ou ecológicos são elaboradas por meio de uma linguagem publicitária, que traz como palavra de ordem "ser sustentável" ou ser "ecopsicossocial". Estes agenciamentos coletivos se

\footnotetext{
"[...] justamente criar rizomas e não raízes, traçar a linha e não fazer o balanço". Significantes... Tudo isso é o rizoma. Pensar, nas coisas, entre as coisas é mesmo que elas retomem noutra parte, saltando por cima dos cortes heterogêneos; fissuras, rupturas imperceptíveis, que quebram as linhas por diferenciação, mas saltam de uma linha a outra" (DELEUZE; PARNET, 1998, p. 22).
}

deliberam em função das variáveis engendradas por um "agenciamento maquínico Natureza-Sociedade", e como Deleuze e Guattari (2011b, p. 27) definem: “é o processo de subjetivação e o movimento de significância que remetem aos regimes de signos ou agenciamentos coletivos. A função-linguagem é transmissão de palavras de ordem, e as palavras de ordem remetem aos agenciamentos [...]".

$\mathrm{E}$, assim, estima-seque o marketing ambiental ou marketing verde elabora os agenciamentos de enunciação para entrega e distribuição de "kits ecológicos" ou "kits de subjetividade verde" (SILVA; TAVARES, 2016), transformando as instituições em empresas com "alma". De outro modo, dito por Kotler, Kartajaya e Setiawan (2010, p. 40): “[...] já não basta atingir apenas a mente. Os profissionais de marketing também precisam atingir o coração dos consumidores".

De acordo com as descrições anteriores, discute-se no tópico seguinte como o marketing psicossocial ancora essa discussão assinalando novas pistas sobre o marketing ambiental.

\section{Do marketing sistêmico ao marketing psicossocial: novas pistas sobre o marketing ambiental}

A Escola de Chicago e a ecologia humana colaboraram com diversas pesquisas no início do século 19, contrapondo-se à sociologia especulativa da Europa de então, procurando tecer novas ferramentas para a análise de atitudes e dos comportamentos humanos (COULON, 1995). Esses estudos visavam compreender as novas formas de comunidade e de vida humana que surgiam na era moderna e que apontavam para uma nova forma de vida econômica regida pelo capital.

Dessa forma, emerge uma nova era "cujos membros vivem uma relação de interdependência mútua de caráter simbiótico" (MATTELART, 2011, p. 31) assumindo novos instrumentos de controle social ou cultural. Esta nova forma de sistematizar e organizar a vida resulta na desintegração das estruturas da sociedade europeia. Neste período, uma grande mobilidade social é registrada promovendo deslocamentos de populações atraídas por melhores condições de vida (COULON, 1995). Em decorrência, a revolução industrial é a virada para um mundo capitalista, que ocasionou uma mudança de paradigma no modo de consumir. Essa nova forma de viver e consumir está relacionada não somente às necessidades básicas de consumo, como também às necessidades psicológicas que acabam por promover o consumo e culminando na era da globalização. Sendo assim, o aparecimento da globalização torna o mundo mais conectado, a produção mundial aumenta em escala, trazendo conseqüências ambientais drásticas,como o aquecimento global e catástrofes naturais. Assim, desde a década passada as organizações voltaram suas estratégias para o marketing ambiental, como forma de impulsionar a sustentabilidade empresarial (ALMEIDA, 2012). Nesse sentido, "A questão ambiental tem-se revelado cada vez mais importante nas relações de troca entre os consumidores e empresas" (DIAS, 2014, p. 19). 
Entretanto, por outro ângulo de visão, evidencia-se que os agenciamentos de enunciação, os quais são operados por intermédio de diversos atores sociais, tais como governos, empresas, fornecedores e mass-media, funcionam como um dispositivo de controle para a capturados desejos dos consumidores "ecoamigáveis" ou "ecopsicossociais". Ou seja, os enunciados das marcas verdes são proferidos como sendo viáveis, justos e ambientais ou, como postulado por Guattari (2001), sob um novo conceito ecosófico (psíquico, social e ambiental). Partindo deste olhar, o conceito ecosófico de Guattari nos adverte para um novo olhar psicossocial do marketing ambiental, num axioma que contradiz o pensamento comumente articulado pela visão positivista.

\section{Considerações finais}

À luz da psicossociologia, este ensaio teve como consideração final a apresentação de um novo olhar sobre o marketing ambiental - que já vem sendo praticado pelas empresas no Brasil - a partir de uma configuração desajustada.

Sobretudo, teve como pressuposto refletir e evidenciar as contradições presentes no processo de agenciamento de enunciação das marcas ecológicas, cujas estratégias comerciais são traçadas por um "rizoma verde", em conjunto com seus stakeholders (fornecedores, consumidores, mass-media, ONGS, órgãos públicos, formadores de opinião etc.).

Dessa forma, este ensaio visou pensar um novo marketing, adverso ao pensamento do marketing sistêmico e das ciências econômicas que se apropria das ciências sociais, da psicologia e da comunicação de modo a trabalhar as subjetividades humanas na captura de novos modos de ser e consumir. Se outrora a estratégia do marketing poderia ser controlada pela empresa, hoje não pode mais. Esse controle escapa dos conceitos teóricos originados por Kotler nos estudos dos 4 Ps (produto, preço, praça e promoção).

Por outro lado, o ensaio apontou que o Capitalismo Mundial Integrado (CMI) necessita do marketing para alimentar o "rizoma verde". E é nesse sentido que o marketing ambiental passa a se aproveitar das redes sociotécnicas; por causa dos fluxos e contrafluxos da comunicação, a estratégia passa a ser um marketing de compartilhamento. Essa nova onda de compartilhamento de informações passa a utilizar os fluxos e contrafluxos da comunicação de massa por meio das redes sociais, num movimento molar/molecular entre as marcas e os seus consumidores. Percebe-se claramente que o marketing ambiental elabora suas estratégias de modo a enaltecer uma marca "alma" que se importa com a natureza, com o impacto socioambiental e com o consumidor. Assim, a nova lógica do marketing ambiental é a lógica do enredamento das redes, da interface de propagar, de difundir, de dividir, de espalhar a comunicação num compartilhamento que é um rizoma da comunicação. O agenciamento de enunciação do marketing ambiental trabalha a subjetividade dos consumidores via interface da comunicação das redes sociotécnicas.
Nesse sentido, este ensaio contribui, também, com uma reflexão que apresenta um contrafluxo epistemológico adotado pelo pensamento da escola francesa, à luz dos preceitos teóricos oferecidos por Gilles Deleuze, Félix Guattari e Bruno Latour, para demonstrar que os agenciamentos de enunciação são elaborados por diversos atores sociais que fazem parte do "rizoma verde". Além disso, o estudo apontou por meio das pistas trilhadas por Guattari e Deleuze, sob a óptica da teoria da esquizoanálise, que a produção de subjetividade do marketing ambiental é constantemente elaborada pelos agenciamentos de enunciação das marcas ecológicas, produzindo "kits de subjetividades verdes", para a captura dos consumidores ecológicos ou "ecopsicossociais".

Destarte, a reflexão filosófica proposta por Guattari considera que a reconstrução das relações humanas deve-se basear na tríade mental, social e ambiental, para que uma nova mudança molar-molecular possa ser realizada em todos os ditames da sociedade contemporânea. Desta forma, propõe-se pensar o marketing ambiental não mais pelo viés do marketing sistêmico das ciências exatas e econômicas que prioriza o lucro acima de tudo, mas sim, por um novo olhar psicossocial que busca confrontar o Capitalismo Mundial Integrado (CMI) de forma ética, priorizando o imperativo de uma mudança socioambiental.

Evidenciou-se, também, que é nesse discurso (enunciado) que o marketing ambiental assume novos comportamentos em relação à temática verde e que as organizações posicionam os seus produtos ecológicos como uma vantagem "verde" competitiva, utilizando dispositivos- tais como: selos verdes, certificações ambientais, discursos ecológicos difusos e ambíguos - para a captura de novos consumidores atraídos pelos "kits de subjetividade verde". O objetivo maior das marcas continua sendo o lucro, não existindo linhas de fuga que apontem para uma saída cuja razão seja poupar os recursos naturais e gerar menor impacto socioambiental de forma global.

Em suma, as pistas teóricas trilhadas neste ensaio apontam para a necessidade de se pensar um novo "marketing ecosófico", que se baseie nas três ecologias (mental, social e ambiental) e seja praticado sob um novo paradigma ético-político e estético (GUATTARI, 2001), priorizando, assim, as relações humanas e socioambientais.

Sobretudo, cumpre ressaltar que, embora existam muitos estudos sobre o marketing sistêmico pensado pelas ciências econômicas da Escola de Chicago, em termos de literatura, não há uma produção relevante sobre a temática do marketing ambiental sob a luz da perspectiva psicossociológica (não positivista). Isto é, o presente ensaio teórico propõe um olhar inédito que, na prática, ajuda a desvendar algumas pistas sobre o marketing ambiental pelo olhar da psicossociologia: ecosofia, rizoma e agenciamento de enunciação.

Destarte, recomenda-se uma investigação futura mais aprofundada sobre o tema, que utilize como pesquisa empírica a cartografia das controvérsias e a Teoria Ator Rede - TAR, já que se trata de uma averiguação que segue processo inacabado de pesquisa. 


\section{Informações sobre os autores:}

Eliane Monteiro de Almeida

(iD) https://orcid.org/0000-0001-8469-8239

(9) http://lattes.cnpq.br/0849915226829636

Doutoranda em Psicossociologia pelo Instituto de Psicologia (Programa EICOS) da Universidade Federal do Rio de Janeiro. Mestre em Administração de Empresas pela Universidade Federal Fluminense - PPGAd/UFF.

Frederico Augusto Tavares Junior

(iD) https://orcid.org/0000-0002-8915-6962

(9) http://lattes.cnpq.br/1047267549932423

Pós-Doutor e Doutor em Psicossociologia pelo Instituto de Psicologia (Programa EICOS) da Universidade Federal do Rio de Janeiro. Professor da Escola de Comunicação, do Instituto de Psicologia (PPG EICOS) e do Instituto de Economia da Universidade Federal do Rio de Janeiro.

\section{Giselle Gama Torres Ferreira}

iD https://orcid.org/0000-0002-1517-7728 http://lattes.cnpq.br/7868741277838679

Doutoranda e Mestre em Psicossociologia de Comunidades e Ecologia Social (Programa EICOS) da Universidade Federal do Rio de Janeiro. Especialista em Marketing pela Escola Politécnica da UFRJ.

\section{Contribuições dos autores}

Todos os autores colaboraram ao longo do processo, desde a elaboração até a revisão final do manuscrito. Os autores aprovaram o manuscrito final para publicação.

\section{Como citar este artigo:}

\section{ABNT}

ALMEIDA, Eliane Monteiro de; TAVARES JUNIOR, Frederico Augusto; FERREIRA, Giselle Gama Torres. Algumas pistas sobre o marketing ambiental pelo olhar da psicossociologia. Fractal: Revista de Psicologia - Dossiê Psicologia e epistemologias contrahegemônicas, Niterói, v. 31, n. esp., p. 269-275, set. 2019. https:/ doi.org/10.22409/1984-0292/v31i esp/28998

APA

Almeida, E. M. de, Tavares Junior, F. A., \& Ferreira, G. G. T. (2019, set.). Algumas pistas sobre o marketing ambiental pelo olhar da psicossociologia. Fractal: Revista de Psicologia - Dossiê Psicologia e epistemologias contra-hegemônicas, 31(esp.), 269 275. doi: https://doi.org/10.22409/1984-0292/v31i esp/28998

\section{Referências}

ALMEIDA, Fernando. Desenvolvimento sustentável 2012 2050: visão, rumos e contradições. Rio de Janeiro: Elsevier, 2012.

CALLON, Michel; LAW, John. L'irruption des non-humains dans les sciences humaines: quelques leçons tirées de la sociologie des sciences et des techniques. In: REYNAUD, Bénédicte (Ed.). Les limites de la rationalité. Paris : La Découverte, 1997. t. 2, p. 99-118.

COUlON, Alain. Escola de Chicago. Campinas: Papirus, 1995.

DELEUZE, Gilles. Conversações. São Paulo: Editora 34, 1992.

DELEUZE, Gilles. Empirismo e subjetividade: ensaio sobre a natureza humana segundo Hume. 2. ed. São Paulo: Editora 34, 2012.

DELEUZE, Gilles; GUATTARI, Félix. $O$ Anti-Édipo: capitalismo e esquizofrenia. Rio de Janeiro: Imago, 2004. v. 1.
DELEUZE, Gilles; GUATTARI, Félix. Mil Platôs: capitalismo e esquizofrenia. 2. ed. São Paulo: Editora 34, 2011a. v. 1.

DELEUZE, Gilles; GUATTARI, Félix. Mil Platôs: capitalismo e esquizofrenia. 2. ed. São Paulo: Editora 34, 2011b. v. 2.

DELEUZE, Gilles; PARNET, Claire. Diálogos. São Paulo: Escuta, 1998.

DIAS, Reinaldo. Marketing Ambiental: ética, responsabilidade social e competitividade nos negócios. 2. ed. São Paulo: Atlas, 2014.

DOMINGUES, Izabela. Publicidade de controle: consumo, cibernética, vigilância e poder. Porto Alegre: Sulina, 2016.

ESCOSSIA, Liliana da; KASTRUP, Virgínia. O conceito de coletivo como superação da dicotomia indivíduo-sociedade. Psicologia em Estudo, Maringá, v. 10, n. 2, p. 295-304, 2005. http://dx.doi.org/10.1590/S1413-73722005000200017.

FERREIRA, Giselle; TAVARES, Fred. Natureza Líquida: as modelagens marcárias e a publicidade verde. Curitiba: Appris, 2017.

FERREIRA, Giselle et al. Green Consumption in Rio de Janeiro: a comparative study between generations $\mathrm{Y}$ and $\mathrm{Z}$. London Journals Press, v. 18, n. 1, p. 1-10, 2017.

GIFFORD, Robert. Environmental Psychology Matters. Annu. Rev. Psychol, v. 65, p. 541-79, 2014. Disponível em: https://www.researchgate.net/publication/256835685 Environmental Psychology Matters. Acesso em: 19 out. 2018.

GUATTARI, Félix. Revolução Molecular: pulsações políticas do desejo. São Paulo: Brasiliense, 1981.

GUATTARI, Félix. Caosmose: um novo paradigma estético. Rio de Janeiro: Editora 34, 1992.

GUATTARI, Félix. As três ecologias. 11. ed. São Paulo: Galilée, 2001.

HARDT, Michael; NEGRI, Antonio. Império. Rio de Janeiro: Record, 2001.

KASTRUP, Virgínia. A rede: uma figura empírica da ontologia do presente. In: PARENTE, A. (Org.). Tramas da rede: novas dimensões filosóficas, estéticas e políticas da comunicação. Porto Alegre: Sulina, 2013. p. 80-90.

KOTLER, Philip; KELLER, Kevin Lane. Administração de marketing. 14. ed. São Paulo: Pearson Education do Brasil, 2012

KOTLER, Philip; KARTAJAYA, Hermawan; SETIAWAN, Iwan. Marketing 3.0: as forças que estão definindo o novo marketing centrado no ser humano. Rio de Janeiro: Elsevier, 2010 .

LATOUR, Bruno. Redifining the social link: from baboons to humans. Social Science Information, v. 26, n. 4, p. 783-802, 1987.

LATOUR, Bruno. Políticas da Natureza. Anuário Antropológico, v. 30, n. 1, p. 171-186, 2005.

LATOUR, Bruno. Reagregando o social: uma introdução à teoria do ator-rede. Salvador: Edufba, 2012.

MATTELART, Armand; MATTELART, Michèle. História das teorias da comunicação. 14. ed. São Paulo: Loyola, 2011.

OTTMAN, Jacquelyn A.; PARO, Marina Nascimento. Marketing verde: desafios e oportunidades para a nova era do marketing. São Paulo: Makron Books, 1994.

Fractal, Rev. Psicol., v. 31 - n. esp., p. 269-275, set. 2019 
PELBART, Peter Pál. Vida capital: ensaios de biopolítica. São Paulo: Iluminuras, 2003.

PONTES, Fernando; TAVARES, Fred. Ecosofia das marcas: as três ecologias na publicidade verde. Curitiba: Appris, 2017.

ROLNIK, Suely. Toxicômanos de identidade: subjetividade em tempo de globalização. In: LINS, Daniel (Org.). Cultura e subjetividade: saberes nômades. Campinas: Papirus, 1997. p. 19-24.

ROLNIK, Suely. Esquizoanálise e Antropofagia. In: ALLIEZ, Eric (Org.). Gilles Deleuze: uma vida filosófica. São Paulo: Editora 34, 2000. p. 451-462.

SILVA, Analice Araujo; TAVARES, Margarete Ribeiro. Exemplos e práticas da produção de "kits de subjetividade verde" como narrativas de modelagens marcárias no consumo da natureza. Revista Espaço Acadêmico, n. 187, p. 23-34, dez. 2016.

STREY, Marlene Neves et al. Psicologia social contemporânea: livro-texto. Petrópolis: Vozes, 2013.

TAVARES, Fred. "Sustentabilidade líquida": o consumo da natureza e a dimensão do capitalismo rizomático nos platôs da sociedade de controle. Revista Sinais Sociais, Rio de Janeiro, v. 9, n. 26, p. 71-95, 2014.

TAVARES, Fred; IRVING, Marta. Do biopoder ao ecopoder: um olhar sobre o consumo verde através dos conceitos de rizoma e sociedade de controle. In: ENCONTRO NACIONAL DA ANPPAS, 5, 2010, Florianópolis. Anais... Florianópolis, SC: ANPPAS, 2010. Disponível em: http://www.anppas.org. br/encontro5/cd/artigos/GT13-316-230-20100901151130.pdf. Acesso em: 22 fev. 2016.

TAVARES, Fred; IRVING, Marta. "Sustentabilidade líquida": ressignificando as relações entre Natureza, Capital e Consumo em tempo de fluidez. Revista Espaço Acadêmico, v. 13, n. 151, p. 1-11, 2013. Disponível em: http://periodicos.uem.br/ojs index.php/EspacoAcademico/article/view/22190. Acesso em: 22 abr. 2014.

TAVARES, Frederico; PONTES, Fernando. Uma breve reflexão sobre as três ecologias e a produção de subjetividade através da publicidade. In: CONGRESSO INTERNACIONAL COMUNICAÇÃO E CONSUMO (COMUNICON), 4., 2014, São Paulo. Anais... São Paulo: 2014. Disponível em: http:// www3.espm.br/download/Anais Comunicon 2014/gts/gt seis/GT06_PONTES.pdf. Acesso em: 3 fev. $201 \overline{6}$

TAVARES, Fred et al. As mulheres vão às compras: um estudo teórico-empírico do comportamento feminino intergeracional e do "consumo verde" no Rio de Janeiro. Revista de administração da UEG, v. 7, n. 1, jan./abr. 2016. Disponível em: https:// www.revista.ueg.br/index.php/revista_administracao/article/ view/3880/3249. Acesso em: 19 out. 2018.

TAVARES, Fred et al. The "Green Consumption" and the Rhizomatic Capital Strategy: Ads and Reports in the Brazilian Media. Advances in Applied Sociology, v. 7, n. 2, p. 35-63, 2017.

VARGAS, Rosa; TAVARES, Frederico. Mídia e consumo: a subjetividade como mercadoria. Curitiba: Appris, 2018. 